\title{
Northern epilepsy syndrome: an inherited childhood onset epilepsy with associated mental deterioration
}

\author{
Aune Hirvasniemi, Heikki Lang, Anna-Elina Lehesjoki, Jaakko Leisti
}

\begin{abstract}
A new autosomal recessively inherited disease of the central nervous system involving childhood epilepsy and mental deterioration is described. Twenty three patients (11 males and 12 females) belonging to 11 families from northern Finland have been identified. A common ancestor has been found for nine families. The mean age of onset of epilepsy was 6.7 years (range 5-10 years) and the epilepsy was characterised by generalised tonic-clonic seizures increasing in frequency up to puberty. One third of the patients also had complex partial seizures during childhood. During young adulthood the epileptic activity began to decrease, but complete remission did not occur. Electroencephalography showed progressive slowing of the background activity with relatively scanty epileptiform activity. Out of four ictal recordings the paroxysmal activity was initiated focally in two cases. Clonazepam and sodium valproate had some antiepileptic effect, clonazepam being the more beneficial of the two. Mental development, which was originally normal, began to deteriorate two to five years after the onset of epilepsy, and the deterioration continued during adulthood in spite of good epilepsy control, leading to mental retardation by middle age. The pathogenesis of the disorder, called the Northern epilepsy syndrome, is unknown. Linkage analysis using DNA markers linked to the EPM1 gene for progressive myoclonus epilepsy of Unverricht-Lundborg type showed that the Northern epilepsy syndrome is not allelic to EPM1.
\end{abstract}

\section{( $(\mathcal{M}$ Med Genet 1994;31:177-182)}

The epilepsies are a clinically and aetiologically heterogeneous group of disorders. Many epilepsies show familial aggregation, but the role of hereditary factors in the aetiology varies. A recurrence risk of 1 to $10 \%$ has been reported in the sibs of an affected subject. ${ }^{1}$ Several types of epilepsy are syndromic, ${ }^{23}$ and epilepsy is often part of an inherited disease of the central nervous system. ${ }^{4}$ In more than 160 mendelian disorders, epilepsy occurs in a proportion of patients as a component of the phenotype. ${ }^{5}$ However, there are only two epilepsy syndromes with a single gene pattern of inheritance ${ }^{6}$ : progressive myoclonic epilepsy of the Unverricht-Lundborg type (EPM1) which displays autosomal recessive inheritance, ${ }^{7}$ and benign familial neonatal convulsions (BFNNC) which is inherited autosomal dominantly. ${ }^{8}$ Unverricht-Lundborg disease has a high incidence in Finland ${ }^{6}$ and the gene (EPM1) has been assigned to a specific region of chromosome $21 \mathrm{q} 22.3$ by linkage and linkage disequilibrium analysis in Finnish families. ${ }^{910}$

We describe clinical, EEG, and pedigree data on a new autosomal recessively inherited epilepsy syndrome, the Northern epilepsy syndrome, diagnosed in 23 patients belonging to 11 Finnish families. The clinical course is characterised by childhood onset tonic-clonic seizures and progressive deterioration in intellectual level.

\section{Families}

The 23 patients studied belonged to 11 families (A to $\mathrm{K}$ ) originating from three neighbouring rural parishes in the region of Kainuu in northern Finland. Pedigrees displaying the relationships between the families are shown in figs 1 and 2 . A common ancestor, who lived in the early 17 th century, was found for both parents in nine families (A-C and E-J, fig 1). The parents in the other two families (D and K) had a common ancestor who lived in the 18 th century (fig 2). Moreover, patient D1 from pedigree 2 was linked to pedigree 1 through his mother. The home villages of the ancestors in pedigrees 1 and 2 were located 30 kilometres from each other.

Of the 23 patients identified $(11$ males and 12 females), 19 were alive. The age range of the living patients was from 10 to 57 years; seven were under 30 and 12 were over 30 years of age. Of the four dead patients, detailed hospital records were available to identify the clinical course of their disorder. In addition, two dead persons with epilepsy and intellectual deficiency were described by some older members of pedigree 1 . This information was confirmed by notes in church registers, but no 


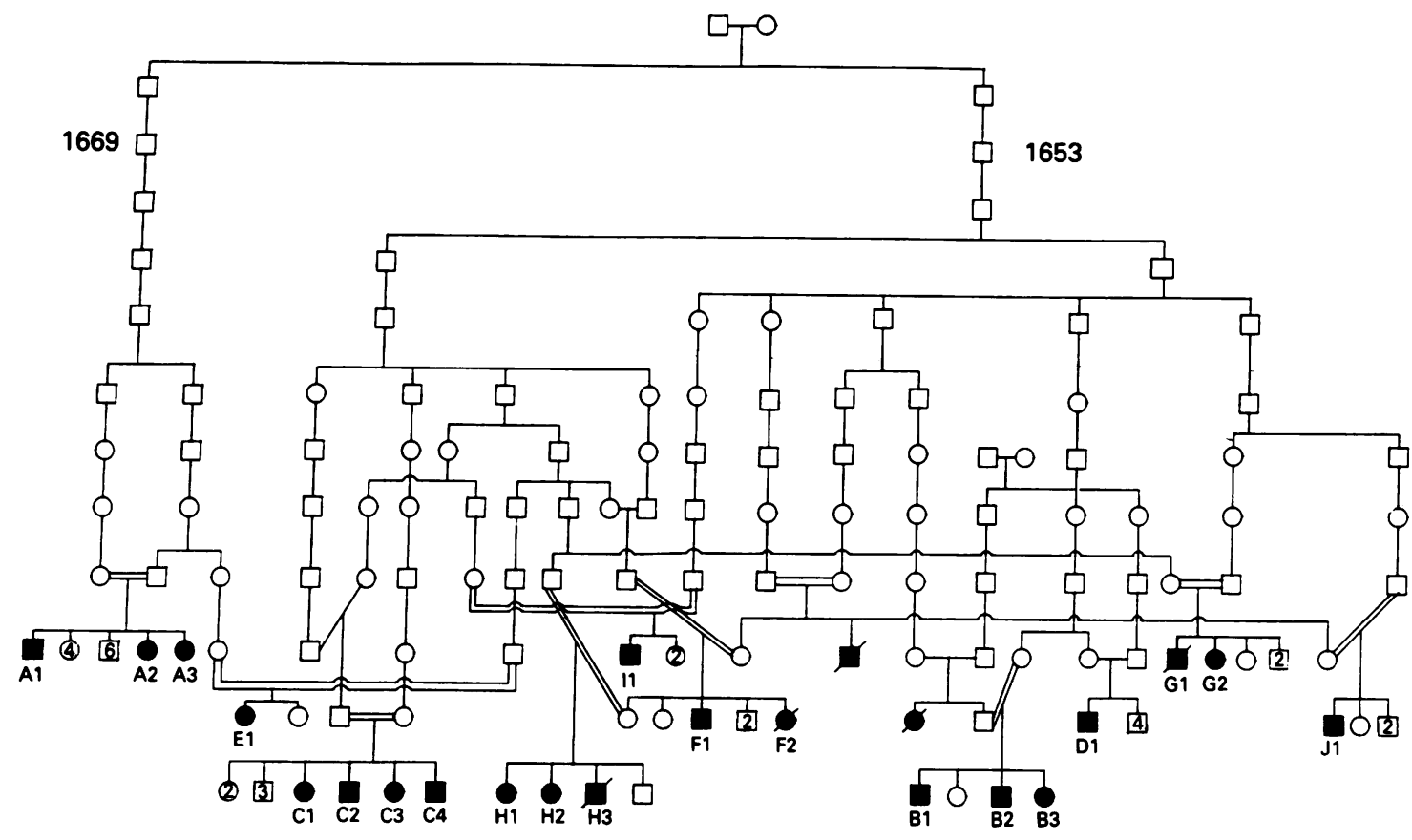

$=$ Consanguineous marriage

Figure 1 Pedigree showing the relationships between families $A$ to $\mathcal{F}$.

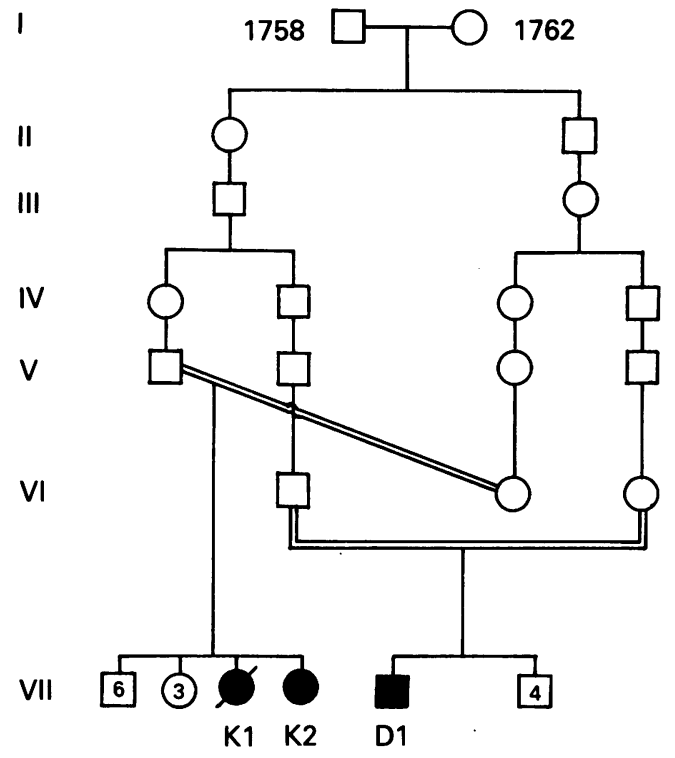

Figure 2 Pedigree showing the relationship between families $D$ and $K$.

hospital records were available. These subjects are marked in pedigree 1 as affected but are given no letter or number symbol. The parents and sibs of the 23 patients studied had no history of seizures.

\section{Clinical features of epilepsy}

The main clinical features are described in the table. All patients suffered from seizures. The mean age of onset of epilepsy was 6.7 years (range 5-10 years) with the exception of one patient (B1), in whom it appeared at the age of 2. This patient had had a two hour long status epilepticus during a febrile illness at the age of
9 months. In seven other patients the first seizure was associated with a febrile condition at the age of 5 to 7 years.

The first attacks were generalised tonicclonic seizures, the frequency being one attack every one to two months. In addition, seven patients had some complex partial seizures during their childhood. The frequency of the seizures increased in spite of antiepileptic medication. During puberty there were on average one or two attacks a week, occurring during both the day and night. After an epileptic attack, nine patients experienced one to three days of mental dullness during which they had to be assisted in their normal daily activities.

At the age of 17 to 25 years the frequency of the epileptic attacks began to decline to one to 25 a year, and from the age of about 35 years to none to four a year, even without change in the medication. However, complete remission of the epilepsy did not occur. There was no difference in the severity of epilepsy between the male and female patients.

\section{Effect of medication on epilepsy}

Initially, all patients were treated with barbiturates, phenytoin, primidone, or carbamazepine, either alone or in combination. None of these prevented the seizures that occurred with increasing frequency. For eight patients sodium valproate was used before and during puberty. It diminished the frequency of seizures in six patients, but the effect only lasted from three months to a few years. Clonazepam, used by 15 patients, had a better effect on the seizures than any of the other drugs used. During clonazepam treatment the patients had 
Main clinical features of the Northern epilepsy syndrome

\begin{tabular}{|c|c|c|c|c|c|}
\hline Family/patient & Present age $(y)$ & Sex & Age of onset (y) & Seizure types & Level of retardation \\
\hline $\begin{array}{l}\text { A1 } \\
\text { A2 } \\
\text { A3 } \\
\text { B1 } \\
\text { B2 } \\
\text { B3 } \\
\text { C1 } \\
\text { C2 } \\
\text { C3 } \\
\text { C4 } \\
\text { D1 } \\
\text { E1 } \\
\text { F1 } \\
\text { G2 } \\
\text { H1 } \\
\text { H2 } \\
\text { I1 } \\
\text { J1 } \\
\text { K2 }\end{array}$ & $\begin{array}{l}37 \\
18 \\
16 \\
33 \\
24 \\
19 \\
35 \\
32 \\
29 \\
27 \\
37 \\
10 \\
57 \\
53 \\
45 \\
43 \\
52 \\
53 \\
38\end{array}$ & $\begin{array}{l}M \\
F \\
F \\
M \\
M \\
F \\
F \\
M \\
F \\
M \\
M \\
F \\
M \\
F \\
F \\
F \\
M \\
M \\
F\end{array}$ & $\begin{array}{l}9 \\
6 \\
7 \\
2 \\
6 \\
6 \\
7 \\
7 \\
9 \\
7 \\
6 \\
6 \\
9 \\
6 \\
7 \\
7 \\
7 \\
5 \\
7\end{array}$ & $\begin{array}{l}\text { GTC } \\
\text { GTC. CP } \\
\text { GTC } \\
\text { GTC, CP, PMD } \\
\text { GTC, CP, PMD } \\
\text { GTC } \\
\text { GTC, PMD } \\
\text { GTC, CP, PMD } \\
\text { GTC } \\
\text { GTC } \\
\text { GTC, PMD } \\
\text { GTC } \\
\text { GTC } \\
\text { GTC, CP } \\
\text { GTC, PMD } \\
\text { GTC, PMD } \\
\text { GTC } \\
\text { GTC, PMD } \\
\text { GTC }\end{array}$ & $\begin{array}{l}\text { Mild } \\
\text { Mild } \\
\text { Borderline } \\
\text { Moderate } \\
\text { Moderate } \\
\text { Borderline } \\
\text { Mild } \\
\text { Severe } \\
\text { Mild } \\
\text { Borderline } \\
\text { Moderate } \\
\text { Borderline } \\
\text { Moderate } \\
\text { Profound } \\
\text { Severe } \\
\text { Severe } \\
\text { Moderate } \\
\text { Severe } \\
\text { Severe }\end{array}$ \\
\hline $\begin{array}{l}\text { Dead patients } \\
\text { F2 } \\
\text { G1 } \\
\text { H3 } \\
\text { K1 }\end{array}$ & $\begin{array}{l}\text { d34 } \\
\text { d37 } \\
\text { d24 } \\
\text { d17 }\end{array}$ & $\begin{array}{l}\mathbf{F} \\
\mathbf{M} \\
\mathbf{M} \\
\mathbf{F}\end{array}$ & $\begin{array}{r}6 \\
5 \\
10 \\
8\end{array}$ & $\begin{array}{l}\text { GTC, CP } \\
\text { GTC, PMD } \\
\text { GTC, CP } \\
\text { GTC }\end{array}$ & $\begin{array}{l}\text { Severe } \\
\text { Severe } \\
\text { Mild } \\
\text { Mild }\end{array}$ \\
\hline
\end{tabular}

$\mathrm{GTC}=$ generalised tonic-clonic seizure, $\mathrm{CP}=$ complex partial seizure, $\mathrm{PMD}=$ postictal prolonged mental dullness .

seizure free periods of one to four years even during puberty and young adulthood when the epilepsy was in its most active phase. The effect of various drugs on the clinical course of the disorder will be reported in detail elsewhere.

\section{Mental development}

Mental development before the onset of epilepsy was normal in 20 patients, whereas three patients were retarded from early childhood. One of them had a two hour long status epilepticus during a febrile illness at the age of 9 months. Another patient had suffered from asphyxia at birth because of placental abruption. No apparent cause for the early developmental retardation was found in the third patient.

Mental deterioration was first observed two to five years after the onset of epilepsy. The decline in the intellectual level was most rapid before adulthood, during the period when the seizures were most frequent. In most cases the patients were transferred to special education or were exempted from compulsory education. Slow deterioration continued even during adulthood, although seizures were infrequent.

At present, four of the 19 living patients are borderline mentally retarded, while four are mildly, five moderately, five severely, and one profoundly retarded (table). The four dead patients had also been mentally retarded as assessed some years before their death.

\section{Other clinical features}

Eleven of the 23 patients had behavioural difficulties in puberty, including irritability, restlessness, disobedience, or inattentiveness. Nine took psychotropic drugs and four spent short periods in mental hospitals, mostly for behavioural disorders. None had overt psychosis.

The neurological examination of three young patients (E1, A3, B3) was normal, while 16 patients displayed slowness and clumsiness in fine motor tasks, as well as difficulties in equilibrium. The physical growth and features of the patients were normal and no dysmorphic features were detected.

\section{Causes of death and necropsy findings}

Four of the 23 patients died. One patient (24 years) suffocated during a seizure attack. The necropsy did not show any specific cause for the epilepsy. Histological specimens of cerebral cortex and pons were re-examined after staining with PAS (periodic acid-Schiff reaction) and Sudan Black. No inclusion bodies such as seen in ceroid lipofuscinosis were detected. Also, myelin was histologically normal (R Herva, personal communication). One patient (34 years) died of traumatic subdural haemorrhage. In addition to the haemorrhage, necropsy showed macroscopically generalised atrophy of the cerebrum (there was no information available on the cerebellum). No microscopic examination was performed. The third patient was drowned at the age of 17 . The fourth patient (37 years) died of pulmonary tuberculosis. In these two cases no necropsy was done.

\section{EEG findings}

Two children had an EEG soon after their first non-febrile seizure attack, with normal results. The later EEG recordings of these patients, as well as those of all the other patients, have been abnormal.

In all 14 patients with serial EEG recordings (total number more than 100) from childhood onwards, a consistent finding was a progressive slowing of the background activity (fig 3), impaired reactivity to eye opening, and a disappearance of specific sleep patterns (vertex waves, $\mathrm{K}$ complexes, and sleep spindles). In the fully developed condition there was hardly any difference between waking and sleep recordings. During puberty the dominant background activity was theta rhythm (5$7 \mathrm{~Hz})$ in 11 patients and theta-slow alpha rhythm $(6-9 \mathrm{~Hz})$ in three patients. In addition, there were mostly posteriorly abundant delta 


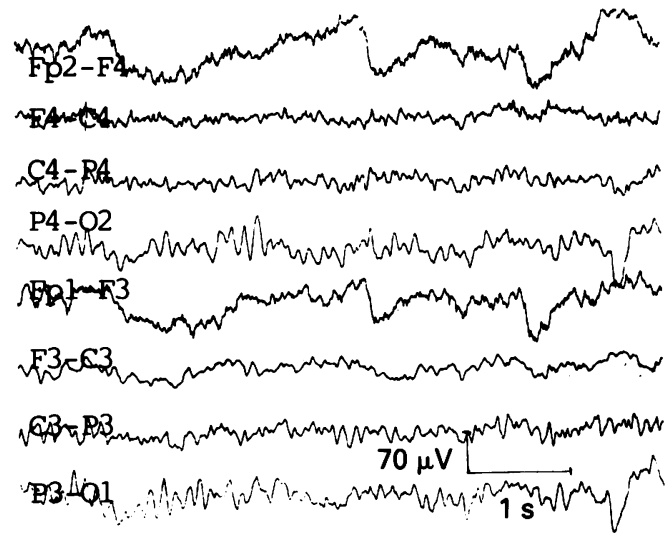

B

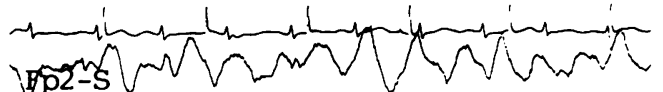

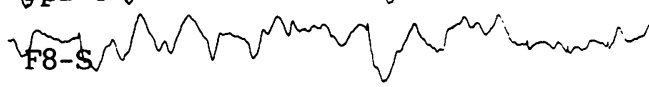
T4-5 T6-S

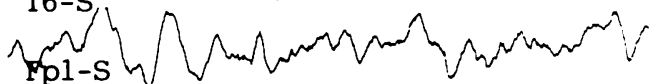

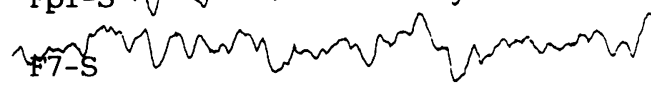

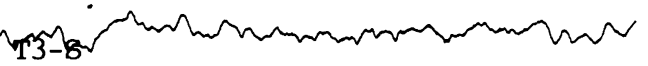
T5:S (100

C

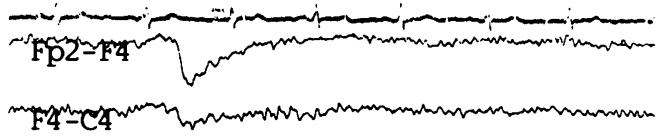

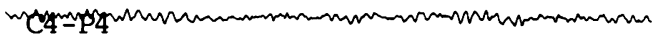

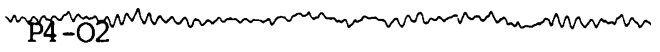

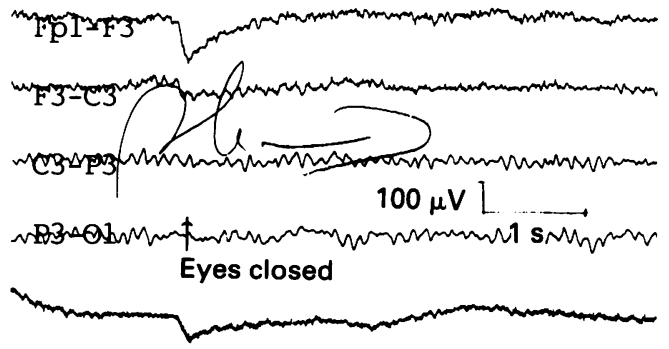

Figure 3 EEG recordings of patient $A 2$ (see pedigree in fig 1) at different ages. (A) Age 7 years, patient awake with eyes closed, (B) age 13 years 5 months, patient awake with eyes open, (C) age 14 years 11 months, patient awake, 18 months after initiation of clonazepam treatment.

waves that often formed irregular paroxysms. By middle age the background activity was theta-slow alpha $(6-9 \mathrm{~Hz})$, and the amount of delta activity was markedly reduced as com- pared to in puberty and young adulthood. The interictal epileptiform findings of all patients were relatively scanty, mostly only small spikes in the midst of irregular paroxysmal delta waves. No constant spike foci were seen. Photic stimulation did not cause either epileptiform discharges or ictal phenomena. Somatosensory and auditory stimulation were not done.

Ictal recordings were available in four patients. Two had asymmetrically initiating, secondarily generalising discharges and one a bilateral synchronous discharge. The nature of the fourth ictal discharge remained unclear. Clonazepam, started at the ages of 8,13 , and 14 years, normalised the EEG of the three youngest patients. The background activity of young adults also became faster after starting clonazepam treatment, although the effect remained weaker than in the youngest patients. Detailed neurophysiological findings will be reported later elsewhere.

\section{Laboratory examinations and computed} tomography

The following laboratory examinations were performed in selected patients during interictal periods, with normal results: blood vacuolated cells $(n=9)$, serum asparate aminotransferase $(n=19)$, alanine aminotransferase $(n=19)$, calcium $(n=17)$, magnesium $(n=8)$, zinc $(n=3)$, copper $(n=11)$, immunoglobulins $(n=12)$, lactate $(n=17)$, pyruvate $(n=7)$, total and free carnitine $(n=3)$, very long chain fatty acids $(n=3)$, phytate $(n=3)$. The plasma values of $\mathrm{N}$-acetyl- $\alpha$-glucosaminidase and arylsulphatase $\mathrm{A}$ of one patient were normal. Urinary screening of amino acids $(n=11)$, oligosaccharides $(n=7)$, glycosaminoglycans $(n=7)$, and organic acids $(n=2)$ also gave normal results. Spinal fluid proteins and cyto$\log y(n=5)$ were normal. A muscle biopsy of one patient was examined both histochemically and by measuring mitochondrial enzymes, with normal results. The karyotypes $(n=5)$ were normal. Cranial CT scans $(n=19)$ already showed evidence of brainstem-cerebellar atrophy in young adult patients and signs of cerebral atrophy in the middle aged patients. The degree of atrophy increased with the duration of epilepsy.

\section{Genetic studies}

In the 11 sibships, there were 66 sibs of whom 23 were affected. The proportion of affected sibs was $0 \cdot 28$, corrected for truncate complete ascertainment by Apert's a priori method, and 0.22 corrected for truncate single ascertainment by omitting one affected sib from each sibship (for terminology and correction methods see Norio $^{11}$ ).

\section{LINKAGE ANALYSIS}

Three multiplex families including 10 affected and nine healthy sibs (A, B, and C, pedigree 1$)$ were studied using marker loci D21S113 and D21S171 which are closely linked to or are in 
strong linkage disequilibrium with EPM1.9 ${ }^{10}$ Several recombinations between the disease phenotype and both markers were detected. The lod scores were negative in all families. The combined lod score $(Z)$ for linkage between the disease phenotype and D21S171 was -13.57 at $\theta=0.001$. Exclusion of linkage $(Z \leqslant-2.00)$ was obtained at a level of $10 \%$ recombination (lod score -2.06 at $\theta=0.10$ ). For D21S113 the lod score was -10.57 at $\theta=0.001$, and exclusion of linkage was reached at a level of $6 \%$ of recombination (lod score -2.04 at $\theta=0.06$ ).

\section{Discussion}

Our patients suffer from an inherited childhood epilepsy syndrome which starts at the age of 5 to 10 years as generalised tonic-clonic seizures and progresses up to early adulthood. One third of the patients also have some complex partial seizures in childhood. In young adulthood the epileptic activity begins to diminish, but clumsiness and difficulties with balance emerge. There is also mental deterioration, starting two to five years after the onset of epilepsy and leading to mental retardation $(\mathrm{IQ}<70)$ by the age of 30 at the latest. CT scanning shows progressive cerebral and cerebellar atrophy. During childhood and young adulthood the seizure attacks can be controlled only by clonazepam and to a lesser extent by sodium valproate.

The EEG pattern typically shows progressively slowing background activity, abundant delta waves and delta paroxysms, lack of sleep spindles, and relatively scanty epileptiform findings. These findings together with missing photic discharges and focally initiated ictal epileptiform activity in two cases clearly differ from the EEG pattern seen, for example, in generalised epileptic syndromes. Moreover, no constant interictal focal (for example, Rolandic) spiking have been found in any of the cases.

The patients belong to two families from the same sparsely populated rural area in northern Finland, and consanguinity was found between all parents. The proportion of affected sibs is 0.28 when corrected for truncate complete ascertainment and 0.22 when corrected for truncate single ascertainment. This agrees well with autosomal recessive inheritance and suggests that the disease is the result of a single gene defect. The occurrence of the disease in northern Finland can be explained by a founder effect and regional isolation with the subsequent enrichment of the gene in the local population. The syndrome may thus be considered to be a further example of the Finnish disease heritage, that is, the enrichment of rare inherited diseases in Finland. ${ }^{12}$

All evidence indicates that this epilepsy syndrome is the result of a progressive disease of the central nervous system. Although the epileptic activity diminishes during adulthood, mental deterioration slowly continues and the degree of cerebral atrophy increases. However, extensive clinical, biochemical, neurophysiological, and radiological studies have so far failed to show any specific pathogenetic mechanisms underlying the disorder.

Two epilepsy syndromes are important from the point of view of differential diagnosis. Firstly, Oller-Daurella and Oller ${ }^{13}$ have described the typical features of a childhood epilepsy with generalised tonic-clonic seizures. It is characterised by a very low seizure frequency $(80 \%$ of patients less than five seizures during their whole lifetime) and normal intelligence in most cases, mental deterioration occurring in only $5 \%$ of cases. A family history of epilepsy exists in $31.2 \%$ of the cases studied. The prognosis is excellent as treatment was suspended in one third of patients over an eight year follow up period. These clinical features are in striking contrast to those of our patients. Secondly, progressive myoclonus epilepsy of the Unverricht-Lundborg type (EPM1, Baltic myoclonus) is the most common inherited form of childhood epilepsy in Finland, the typical age of onset being 6 to 15 years. ${ }^{14}$ As in our patients, the EEG of EPM1 patients shows an abnormally slow background activity, and there is a good response to sodium valproate and clonazepam therapy. However, our patients do not have stimulus sensitive myoclonic jerks, and no abnormal photosensitivity has been observed on the EEG. Also, the deterioration in mental capacity during the school years is much slower in EPM1 than in our patients. The assignment of the EPM1 gene to chromosome 21q22.3910 allowed us to test whether the Northern epilepsy syndrome and EPM1 are also different at the molecular level. Three multiplex Northern epilepsy families were tested for linkage to two markers from the EPM1 region. ${ }^{910}$ Convincingly negative lod score values were obtained for both markers studied. The localisation of Northern epilepsy was excluded at a distance of $10 \mathrm{cM}$ on either side of D21S171 and of $6 \mathrm{cM}$ of D21S113. As these markers reside in the $7 \mathrm{cM}$ EPM1 region $^{10}$ with a distance of $6 \mathrm{cM}$ between them, ${ }^{15}$ the linkage data indicate that the EPM1 gene is not the gene causing the Northern epilepsy syndrome. Thus these two epilepsy syndromes are separate genetic as well as clinical entities. In addition to the two epilepsy disorders discussed above, the onset of epilepsy at the age of 5 to 10 years, its progressive course up to puberty, and the associated mental deterioration seen in the Northern epilepsy syndrome are not characteristic features of any other epileptic syndrome of childhood. ${ }^{16}$

In general, there is little evidence of deterioration in the intellectual level in well controlled seizure disorders. ${ }^{17}$ However, poor seizure control and repeated generalised tonicclonic seizures can be associated with mental impairment. ${ }^{17}$ It has been suggested that in these cases both of the symptoms are related to an underlying neurological dysfunction. ${ }^{18}$ On the other hand, antiepileptic drugs, especially phenobarbital and phenytoin, often affect interictal cognitive function, although the effect is usually fairly subtle. ${ }^{18}$ Individual patients, however, may be particularly sensitive to the cognitive side effects of certain 
drugs. In our patients, the time interval between the onset of epilepsy and the mental changes was only a few years. Moreover, the degree of mental deterioration was very marked and was thus unlikely to be caused by the medication. As the disease could involve an increased sensitivity to the $\operatorname{drug}(\mathrm{s})$ used, an adverse effect of medication cannot be totally ruled out.

Although genetic in nature, the underlying cause and pathogenetic mechanisms of the Northern epilepsy syndrome are not yet known. Nevertheless, it is important to delineate the various clinical entities among childhood epilepsies. By doing this one can correctly inform the families about the clinical features, the risk of recurrence, and the prognosis of the disorder. Moreover, it enables one to select the drug of choice for that particular clinical situation.

This work was supported by the Arvo and Lea Ylppö Foundation.

1 Blandfort M, Tsuboi T, Vofel F. Genetic counseling in the epilepsies. I Genetic risks. Hum Genet 1987;76:303-31.

2 Gram L. Epilepsy octet. Epileptic seizures and syndromes. Lancet 1990;336:161-3.

3 Wallace SJ. Epilepsy octet. Childhood epileptic syndromes. Lancet 1990;336:486-7.

4 Bird TD. Genetic considerations in childhood epilepsy. Epilepsia 1987;28(suppl 1):S71-81.

5 Anderson VE, Hauser WA, Olafsson E, Rich SS. Genetic aspects of the epilepsies. In: Sillanpää $M$, Johannessen aspects of the epilepsies. In: Sillanpaa $M$, Johannessen field: Wrightson Biomedical Publishing, 1990:37-56.
6 Gardiner RM. Genes and epilepsy. $f$ Med Genet 1990;27:537-44.

7 Norio R, Koskiniemi M. Progressive myoclonus epilepsy: genetic and nosological aspects with special reference to 107 Finnish patients. Clin Genet 1979;15:382-98.

8 Plouin P. Benign idiopathic neonatal convulsions (familia and non-familial) In: Rer J, Bureau $M$, familial and nus FE Perret A Wolf P, J, Bureau M, Dravet C, infancy, childhood and adolescence. London: John Libbey, infancy, child

9 Lehesjoki AE, Koskiniemi M, Pandolfo M, et al. Linkage studies in progressive myoclonus epilepsy: UnverrichtLundborg and Lafora's diseases. Neurology 1992;42:1545-50

10 Lehesjoki AE, Koskiniemi M, Norio R, et al. Localization of the EPM1 gene for progressive myclonus epilepsy on chromosome 21: linkage disequilibrium allows high resolution mapping. Hum Mol Genet 1993;2:1229-34.

11 Norio R. Heredity in the congenital nephrotic syndrome. A genetic study of 57 Finnish families with a review of reported cases. Ann Paediatr Fenn 1966;12:suppl 27.

12 Norio R, Perheentupa J, Nevanlinna H. Hereditary diseases in Finland; rare flora in rare soil. Ann Clin Res 1973;5:109-41.

13 Oller-Daurella L, Oller LFV. Epilepsy with generalized tonic-clonic seizures in childhood. Does a childhood 'grand mal' syndrome exist? In: Roger J, Bureau M, 'grand mal' syndrome exist? In: Roger J, Bureau M, syndromes in infancy, childhood and adolescence. London: John Libbey, 1992:161-71.

14 Koskiniemi M. Progressive myoclonic epilepsy. In: Sillanpää M, Johannessen SI, Blennow G, Dam M, eds. Paediatric epilepsy. Petersfield: Wrightson Biomedical Publishing, 1990:137-44

15 Petersen M, Weber JL, Slaugenhaupt SA, et al. Linkage mapping of D21S171 to the distal long arm of human chromosome 21 using a polymorphic (AC)n dinucleotide repeat. Hum Genet 1991;87:401-4.

16 Roger J, Bureau M, Dravet C, Dreifuss FE, Perret A, Wolf $\mathrm{P}$, eds. Epileptic syndromes in infancy, childhood and adolescence. London: John Libbey, 1992.

17 Brown ER. Interictal cognitive changes in epilepsy. Semin Neurol 1991;11:167-74.

18 Smith DB. Cognitive effects of antiepileptic drugs. In: Smith D, Treiman D, Trimble M, eds. Advances in Smith D, Treiman D, Trimble M, eds. Advances in
neurology. Vol 55. New York: Raven Press, 1991:197-212. 